\title{
Panorama actual del patrimonio geológico en Argentina
}

\author{
Current situation of geologiacal heritage in Argentina \\ FERNANDO MIRANDA, HEBE LEMA.
}

SEGEMAR, Argentina - fjmiran@gmail.com - hlema@minplan.gov.ar

\begin{abstract}
Resumen
La República Argentina cuenta con una larga historia en cuestiones de protección del patrimonio natural. No obstante, dentro de este campo, el concepto más específico de patrimonio geológico es relativamente nuevo. Su tratamiento más integral comenzó a partir del inicio de la década del 90, momento en el cual, instituciones y profesionales de diversos ámbitos, abordaron el interés por la temática. Muchos han sido los esfuerzos individuales, pero en la actualidad se torna necesario un trabajo conjunto, con continuidad en tiempo y bajo un marco legal adecuado. La presente contribución constituye una puesta al día de algunas acciones realizadas, otras que se están llevando a cabo y el ensayo de algunas reflexiones acerca del futuro en este contexto.
\end{abstract}

Palabras clave: Patrimonio geológico; Geología; Argentina.

\begin{abstract}
The Republic of Argentina has a long history in what concerns natural heritage protection. However, the more specific concept of geological heritage is relatively new. Its comprehensive treatment began in early 90 s, when some institutions and professionals from various domains developed an interest for this topic. Many have been individual efforts but today it is necessary to work together with continuity in time and under a proper legal framework. This contribution presents an update of some actions done in recent years and others being presently carried out. Finally, some thoughts about the future of geoconservation in Argentina are presented.
\end{abstract}

Key words: Geological heritage; Geology; Argentina.

\section{INTRODUCCIÓN}

La República Argentina se extiende desde los Andes hasta la cuenca del Plata y la plataforma submarina, y desde la llanura chaqueña y la altiplanicie de la Puna hasta la Antártida. La amplia extensión en latitud y longitud y su ubicación geográfica en el hemisferio austral, le otorga, dentro del ámbito de América del Sur, una gran variedad de geografías y climas y la posibilidad de transitar y admirar escenarios naturales imponentes. Este abanico de paisajes es el resultado de diferentes procesos geológicos que han actuado a lo largo de millones de años y que han dejado testimonio de épocas que abarcan desde los primeros tiempos del Proterozoico hasta eventos geológicos recientes. Muchos de estos paisajes son majestuosos, pero muchos de ellos también son frágiles en extremo. Algunos de ellos albergan o constituyen en sí mismos sitios de interés geológico, entendiendo por tales a aquellos cuya exposición y contenido son especialmente adecuados para reconocer e interpretar las características y la evolución de los procesos geológicos que han modelado nuestro planeta. Estos sitios forman parte del conjunto de recursos naturales de valor científico, cultural, educativo y recreativo que aunamos bajo la idea de patrimonio geológico.

\section{LOS ANTECEDENTES EN ARGENTINA}

Así como el concepto de patrimonio se ha impuesto de modo evidente tanto en la vida cultural como en las políticas públicas mundiales de los últimos decenios, en el caso de la República Argentina puede decirse que la protección del patrimonio natural cuenta con una larga historia. Ya en el año 1913, la sanción de la ley 9.080 fue un hito interesante. Esta ley, aunque nunca fue realmente aplicada y hoy en día ha sido superada, fue la primera en declarar como propiedad de la Nación las ruinas y yacimientos arqueológicos y paleontológicos de interés científico (Endere \& Podgorny 1997).

Para esa época también comenzaban a sumarse las inquietudes de naturalistas y profesionales geólogos por la conservación de los espacios naturales. En este sentido, cabe mencionar como ejemplo al Dr. Juan José Nágera, uno de los primeros geólogos argentinos, que en 1932, en ocasión de la publicación de la carta geológica de Tandilia (provincia de Buenos Aires), menciona como una necesidad la creación de Parques Naturales en esa región en bien de la comunidad. En sus propias palabras dice Nágera: “...deberá conservarse la naturaleza original facilitándose en toda forma el paseo por los mismos. Deberán publicarse además guías que expliquen su historia natural..." (Cingolani 2008). Actualmente la región de Tandilia es considerada un geositio de 
importancia nacional ya que allí se encuentran las rocas y fósiles más antiguos del país.

Sin duda uno de los acontecimientos más importantes en el sentido de protección del patrimonio natural fue la sanción de la ley 12.103 (9 de octubre de 1934) por la cual se creó la Dirección de Parques Nacionales. Esta permitió la creación de los Parques Nacionales Nahuel Huapi e Iguazú, convirtiendo a la Argentina en el primer país de Latinoamérica y tercero en el mundo en crear Parques Nacionales, luego de los Estados Unidos (Parque Yellowstone, 1872) y Canadá (Parque Banff, 1885). Un detalle de interés para la época, es la aparición de la guía geológica del Parque Nacional Nahuel Huapi (Primo 1951) cuyo estilo de escritura está dirigido al público en general (Figura 1).

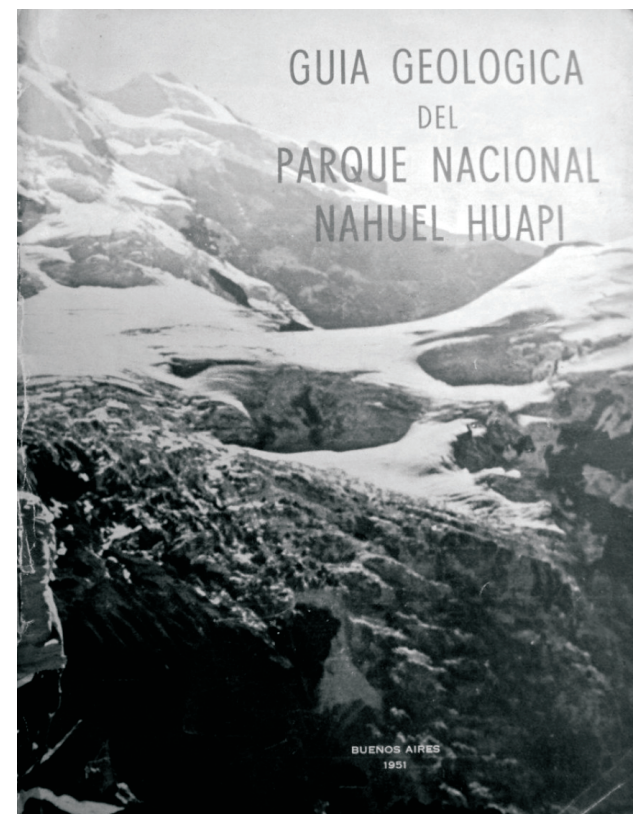

Figura 1 - Detalle de la tapa de la Guía Geológica del Parque Nacional Nahuel Huapi (Primo 1951).

Dentro del campo del patrimonio natural, el concepto más específico de patrimonio geológico es relativamente nuevo en Argentina. No obstante, al incluir en él al patrimonio minero y al paleontológico, vemos que este último contó con leyes de protección desde 1913: ley 9.080 y a partir del año 2003 con la nueva ley 25.743. Más allá de esta salvedad, el tratamiento del patrimonio geológico en su integridad comenzó mas exhaustivamente a partir de la década de los años 90, momento en el cual, instituciones y profesionales de diversos ámbitos, abordaron el interés y compartieron una preocupación por la conservación de esta herencia.

En particular, el Servicio Geológico Minero Argentino (SEGEMAR) a partir de la promulgación en 1993 de la Ley 24224, que establece en su Capítulo I "De las Cartas Geológicas" la necesidad de realizar la investigación geológica regional sistemática del país a través de un Programa Nacional de Cartas Geológicas, incorpora en cada Hoja Geológica un capítulo exclusivo sobre Sitios de Interés Geológico (SIG), definidos éstos como recursos no renovables de índole cultural, cuya exposición y contenido resultan óptimos para reconocer e interpretar el diseño de los procesos geológicos que han modelado nuestro planeta. Además, en la normativa establecida para la ejecución de las Hojas, se señala que su conjunto conforma el patrimonio geológico de cada región y del país, destacando incluso que la importancia de algunas singularidades geológicas puede ser de valor supranacional (SEGEMAR-IGRM, 1994).

Agrega también que su desaparición o tratamiento inadecuado constituye un gran daño al patrimonio de la humanidad, daño que la mayoría de las veces es irreversible. Con posterioridad, y como anexo de la normativa, se incorporaron y modificaron fichas descriptivas para el relevamiento y catalogación de los sitios (SEGEMAR-IGRM, 1997). Esto permitió que la Institución reuniera gran cantidad de información acerca de estos lugares y hasta el momento lleva inventariados más de trescientos cincuenta sitios de interés.

Como mencionáramos anteriormente, la idea de patrimonio geológico es relativamente reciente en Argentina y ha surgido (o si se quiere resurgido) a partir de las nuevas tendencias europeas, y en simultaneidad con trabajos y proyectos realizados en escenarios latinoamericanos. Esto ha fomentado, durante los últimos años, la aparición de trabajos de carácter local en diversas ramas de la temática, tales como sitios de interés geológico, geoturismo y parques geológicos, entre otros.

Dentro de los antecedentes vinculados al patrimonio geológico y su conservación, uno de los casos destacables es sin duda el vinculado al aspecto patrimonial y de geoconservación del Monumento Natural Puente del Inca, merecedor de un simposio especial dentro del XII Congreso Geológico Argentino y II Congreso de Exploración de Hidrocarburos llevados a cabo en la provincia de Mendoza en el año 1993.

Enmarcado en el ámbito de la Cordillera Principal de Mendoza, el denominado Puente del Inca, uno de los caprichos naturales más famosos de la República Argentina (Figura 2), es una compleja estructura natural en forma de puente en arco, cuyo origen y perdurabilidad se debe, entre otras condiciones, a la presencia de aguas termales en el área (Ramos 1993, Rubio et al. 1993, Aguirre Urreta \& Ramos 1996, Ramos et al. 2008). Hasta la construcción del hotel y estación de baños termales que funcionara hasta 1965, el puente constituía un sistema natural en equilibrio. La captación de las aguas termales hacia el establecimiento para los baños y el empleo de zanjas de desvío para la confección de artesanías mermaron la irrigación natural sobre el puente, provocando el desecamiento y agrietamiento de su parte superior. Simultáneamente, el tránsito de animales y vehículos aceleró su erosión e inició el 
paulatino deterioro de su estructura, poniendo al puente en una situación de inestabilidad. En 1991 el gobierno provincial declaró al monumento natural "zona intangible" mediante decreto 2291/91. Es interesante destacar la valorización que se hace de este monumento en el decreto de referencia, el cual plantea:"...la necesidad de solucionar en forma inmediata el problema suscitado por el deterioro que presenta la estructura geológica del puente natural existente en la localidad cordillerana de Puente del Inca, monumento provincial, nacional y universal, objeto de admiración generalizada y fuente de recursos turísticos del patrimonio de la Provincia de Mendoza". Por intermedio de tal decreto se restringió el paso de animales y vehículos, procediendo luego, entre otras obras, al relleno de grietas con sales provenientes del agua termal, la eliminación de bloques rocosos del lecho del río y la reactivación del drenaje natural de las aguas termales sobre la estructura del puente (Rimoldi 1993), algo que podríamos considerar como caso de "Geo-restauración" del patrimonio geológico.

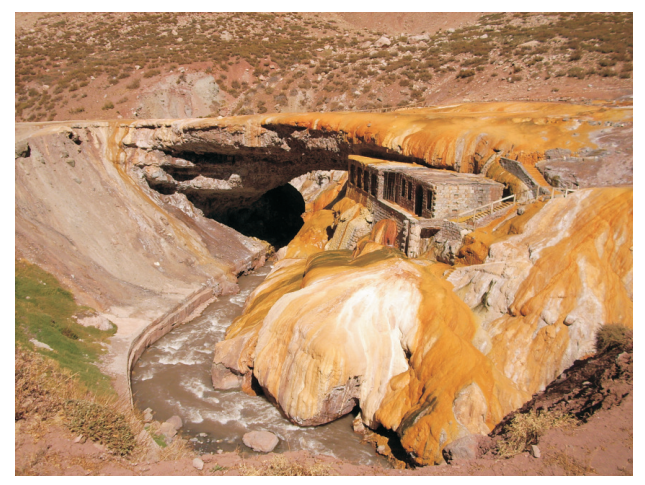

Figura 2 - Monumento natural Puente del Inca, provincia de Mendoza. A una altura de 2.719 metros sobre el nivel del mar, las aguas termales y esta curiosa formación natural de puente en arco ya eran conocidas desde tiempos precolombinos por quienes habitaban el imperio incaico. Muchos fueron los viajeros, naturalistas e investigadores -entre ellos Charles Darwin- que dedicaron páginas a este singular paisaje. La cobertura del puente está compuesta por sustancias minerales y costras algáceas. Si bien las hipótesis sobre el origen de este puente son variadas, todas señalan a las sales contenidas en las aguas termales como partícipes necesarios en su formación y perdurabilidad (Fotografía por Luis Fauqué).

\section{LEGISLACIÓN}

Varios son los autores que señalan que en Argentina la información disponible y las propuestas para la conservación del patrimonio natural se refieren predominantemente a aspectos biológicos, no recibiendo la misma atención los recursos relacionados con los paisajes y sus formas, los procesos y rocas, a excepción de aquellos que han quedado dentro de áreas protegidas o que se consideran Monumentos Naturales
(Ley Nacional 22.351/80 “Parques Nacionales, Monumentos Naturales y Reservas Nacionales") (Ibáñez Palacios et al. 2012).

En la actualidad, no hay herramientas legales del ámbito nacional directa y estrictamente vinculadas al patrimonio geológico, pero sí algunas que pueden ayudar a su inclusión. En este sentido, la Ley Nacional 25.675/02, Ley General del Ambiente, sancionada el 6 de noviembre de 2002 y promulgada parcialmente el 27 de Noviembre de ese año, persigue entre otros objetivos: Asegurar la preservación, conservación, recuperación y mejoramiento de la calidad de los recursos ambientales, tanto naturales como culturales, en la realización de las diferentes actividades antrópicas (art $2^{\circ}$ inciso a.). La Ley Nacional 25743/03 de "Protección del patrimonio arqueológico y paleontológico", promulgada en junio de 2003, establece en su articulo $1^{\circ}$ que su objeto es la preservación, protección y tutela del Patrimonio Arqueológico y Paleontológico como parte integrante del Patrimonio Cultural de la Nación y el aprovechamiento científico y cultural del mismo. En su artículo $2^{\circ}$ aclara que: forman parte del Patrimonio Arqueológico las cosas muebles e inmuebles o vestigios de cualquier naturaleza que se encuentren en la superficie, subsuelo o sumergidos en aguas jurisdiccionales, que puedan proporcionar información sobre los grupos socioculturales que habitaron el país desde épocas precolombinas hasta épocas históricas recientes, y en relación al Patrimonio Paleontológico los organismos o parte de organismos o indicios de la actividad vital de organismos que vivieron en el pasado geológico y toda concentración natural de fósiles en un cuerpo de roca o sedimentos expuestos en la superficie o situados en el subsuelo o bajo las aguas jurisdiccionales. En tal sentido, entre las facultades señaladas en su artículo $4^{\circ}$ se encuentra que será exclusividad del Estado Nacional: ejercer la tutela del Patrimonio Arqueológico y Paleontológico. En orden a ello deberá adoptar las medidas tendientes a su preservación, investigación y a fomentar la divulgación.

Medina (2012) analiza la presencia del término "geología" en las leyes de Áreas Protegidas provinciales con el fin de resaltar la importancia de la presencia o ausencia de este término dentro de una ley, de manera que la misma no resulte ambigua.

Así este autor señala términos como el de "formaciones geológicas y geomorfológicas" como objetos a preservar (provincias de Buenos Aires, Córdoba, Chaco, Chubut, La Pampa, Mendoza, Neuquén, Rio Negro, Salta, San Juan y San Luis); "formaciones fisiográficas" (provincias de Catamarca, Entre Ríos, Jujuy, La Rioja y Tierra del Fuego, donde también se utilizó la denominación subjetiva de paisaje de gran valor escénico). Y encuentra una tercera situación en las leyes de las provincias de Formosa Ley 1335/00, Misiones Ley 2932/92 y Tucumán Ley 6292 donde no se incluyen términos geológicos ni tampoco sobre aspectos 
escénicos del paisaje.

\section{EL PATRIMONIO GEOLÓGICO Y LA COMUNIDAD GEOLÓGICA}

La aparición de la temática de sitios de interés geológico durante un Congreso Geológico Argentino se dio por primera vez en la XV edición de esa reunión científica, en el año 2002, en la provincia de Santa Cruz. El Relatorio o compendio de la geología de la provincia anfitriona del evento, incluyó un extenso trabajo en referencia a 127 sitios de interés geológico distribuidos en todo el territorio provincial. Los sitios seleccionados surgieron de los incluidos en las hojas geológicas a escala 1:250.000 del SEGEMAR y de la contribución y orientación de profesionales con experiencia en la región. El trabajo se desarrolló bajo el criterio de itinerarios que recorrían grupos de sitios (Ardolino et al. 2002).

En ocasión de esa reunión también tuvo lugar el I Simposio de Patrimonio Geológico y Aspectos Geológicos y Ambientales de la Espeleología. Los trabajos allí presentados abordaron diferentes temas. Entre ellos: el inventario y caracterización de 28 puntos de interés geológico del territorio de la provincia de Córdoba -junto a propuestas para su aprovechamiento y su protección(Leynaud 2002); una propuesta de valoración turística recreativa de recursos geológicos, paleontológicos y paisajísticos en la ciudad de Neuquén para el proyecto (no concretado) Monumento Natural Parque de los Dinosaurios (Vejsbjerg et al. 2002); el relevamiento de áreas de valor científico, cultural y estético en riesgo ante la realización de obras de infraestructura en la localidad de Nogolí, provincia de San Luis (Lacreu et al. 2002) y el análisis de la potencialidad y posibilidades de desarrollo de los georecursos del Parque Nacional Talampaya (Caselli 2002) (Figura 3).

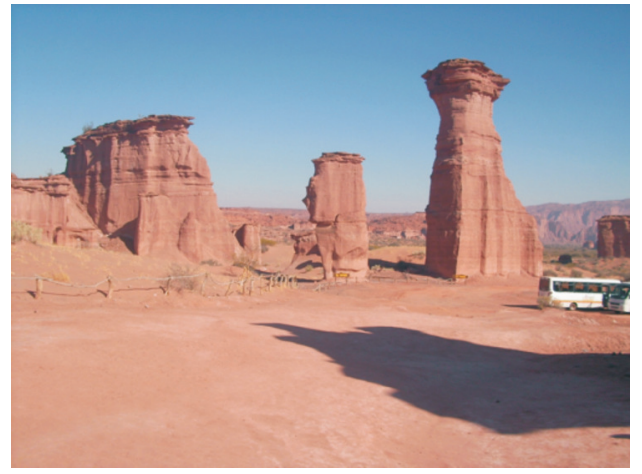

Figura 3 - El Parque Nacional Talampaya, en el sudoeste de la provincia de La Rioja, es una extraordinaria reserva paleontológica y uno de los pocos yacimientos en el mundo que contiene un interesante y completo registro de vertebrados fósiles que permite explicar su evolución y el desarrollo de la vida en la región durante todo el período Triásico. Tal contenido, junto a un interesante conjunto de geoformas de inconmensurable belleza lo posicionó como Patrimonio Natural de la Humanidad de UNESCO (Caselli 2008) (Fotografía por Fernando Miranda).
Ya en el año 2005, el XVI Congreso Geológico Argentino (La Plata, provincia de Buenos Aires), incorpora la temática de Sitios de Interés Geológico. En el encuentro surgen trabajos vinculados al inventario de 44 sitios de interés en la provincia de Entre Ríos (Bertolini et al. 2005) y otros 30 en la provincia de San Juan. Estos últimos, seleccionados en el marco del Proyecto "Identificación y Valoración del Patrimonio Geológico de la Provincia de San Juan, su Proyección Científica, Cultural, Educativa y Turística" 2003-2005 (Baraldo et al. 2005).

Contrariamente a lo esperado, para el año 2008 la edición del XVII Congreso Geológico Argentino (en la provincia de Jujuy) no incluyó el capítulo Sitios de Interés Geológico o alguno equivalente. A pesar de ello, trabajos relacionados participaron en el Simposio de Enseñanza de la Geología, encuentro durante el cual se presentaron propuestas para la implementación de circuitos de interés geológico en la Cuenca Carbonífera de Río Turbio, en la provincia de Santa Cruz (Tello \& Defago 2008), experiencias vinculadas al trabajo social y la transferencia de conocimientos geológicos a comunidades locales en la provincia de San Juan (Vallecillo et al. 2008), y un proyecto piloto de implementación de paneles temáticos in situ en la Reserva Laguna del Diamante, provincia de Mendoza (Miranda \& Sáenz 2008).

No obstante la ausencia de un simposio especifico en el Congreso, durante su desarrollo se presentó la obra "Sitios de Interés Geológico de la República Argentina - Los geólogos nos cuentan..." editado por el SEGEMAR y al cual nos referimos mas adelante en mayor detalle.

Simultáneamente a la aparición del Patrimonio Geológico como tema de congresos y reuniones científicas, varias universidades nacionales comenzaron a abordar esta materia. A modo de ejemplo, la provincia de San Luis incorpora capítulos de geositios en los Atlas de Recursos Geoambientales de las localidades de Potrero de Funes y Juana Koslay, (Ojeda et al. 2007, 2008). También la Universidad Nacional de La Plata, a través de publicaciones de la Facultad de Humanidades y Ciencias de la Educación, abordó la propuesta y necesidad de realización de un inventario de patrimonio geológico nacional (Martínez 2008).

Para el año 2011, el XVIII Congreso Geológico Argentino, realizado en la provincia de Neuquén, volvió a presentar la temática de patrimonio, geositios, geoturismo y geoparques. Es así que en el Relatorio de la provincia se incorporó un capitulo exclusivo dedicado a la descripción de un total de 32 sitios o áreas provinciales destacadas desde el punto de vista geológico-patrimonial (Danieli et al. 2011). A su vez, durante el desarrollo del Congreso, el Simposio (S9) -Patrimonio natural y Cultural en su Contexto Geológico- reunió un interesante conjunto de trabajos. Entre ellos: propuestas de incorporación de atractivos geológicos a circuitos turísticos tradicionales, como en el caso del cerro San 
Bernardo en la provincia de Salta (Barrientos Ginés \& Moya 2011), varios vinculados a la dupla e interacción entre arqueología y geología (Brandán et al. 2011, Tchilinguirian et al. 2011, Vattuone Sampietro et al. 2011), propuestas de rutas geoturísticas (Ermili \& Martínez 2011, Guido \& Sesma 2011), reflexiones acerca de cuestiones de patrimonio geológico, paisaje natural y el rol profesional en este tipo de cuestiones (Kulemeyer 2011, Neder \& Ríos 2011), propuestas de geositios específicos, como Rosario de La Frontera en la provincia de Salta y el rol del termalismo del área vinculado al desarrollo histórico de la región (Ríos \& Neder 2011), inventario y evaluación de geositios en la Quebrada del Portugués, provincia de Tucumán (Palacios et al. 2011), la relación entre afloramientos rocosos específicos y especies vegetales amenazadas (Cantero et al. 2011), casos de estudio y recomendaciones para el manejo y gestión del patrimonio geológico y paleontológico (Iparraguirre \& Oliva 2011, Goso et al. 2011) y el trabajo social a partir de la geología en La Cienaga de Huaco, provincia de San Juan (Vallecillo \& Caballero 2011), lugar declarado como Área Natural Protegida por la Cámara de Diputados de la provincia en el año 2005 (ley 7.640). En este último caso el área protegida, de unas 9.600 hectáreas, tiene por objeto preservar el valor geológico y arqueológico, el equilibrio ecológico y el patrimonio autóctono del lugar. En el sitio pueden observarse formaciones geológicas de gran interés sedimentológico y fósiles de edad ordovícica.

Trabajos más recientes incluyen la presentación del primer circuito de geoturismo en la provincia de Córdoba, y primero con carácter oficial en el país; iniciativa coordinada entre la Dirección de Geología de la Secretaría de Minería de Córdoba y la Agencia Córdoba Turismo (Sfragulla et al. 2010). El circuito se desarrolla a lo largo de 120 km sobre la Ruta Provincial № 28, entre las localidades de Tanti y Chancaní. Posee una dirección general este-oeste que atraviesa las principales unidades geológicas aflorantes en ese sector de las Sierras Pampeanas de Córdoba y cuenta con 14 puntos de interés geológico y/o paisajístico con paneles informativos sobre los aspectos geológicos del lugar. Entre ellos: el Batolito de Achala, intrusión granítica de edad devónica (principal unidad geológica de la región); yacimientos pegmatíticos ricos en minerales de colección; el contacto del Batolito con rocas metamórficas de edad cámbrica inferior; el Complejo Volcánico de Pocho, compuesto por traquiandesitas neógenas y uno de los lugares panorámicos mas espectaculares de la Sierra de Córdoba, conocido como Los Túneles, que como su nombre lo indica resultan en una serie de túneles excavados en rocas metamórficas de la Sierra de Pocho (Sapp et al. 2008).

Otro nuevo aporte es el inventario preliminar relacionado con criogeoformas cuaternarias de la región del Parque Nacional Campo de Los Alisos (Sierra del Aconquija) en las provincias de Tucumán y Catamarca cuyo objetivo, además de divulgar y contribuir a la preservación de ese patrimonio geológico, plantea la posibilidad de generar recursos para la actividad turística (Ibáñez Palacios et al. 2012). Una de las contribuciones más recientes corresponde a un trabajo integral que abarca propuestas de geoconservación aplicables a la República Argentina -tomando como base las prácticas de esta temática en España, Portugal y el Reino Unido- e ideas para la realización del inventario sistemático del patrimonio geológico argentino y su respectiva evaluación cuantitativa (Medina 2012).

\subsection{Patrimonio Minero}

Dentro del contexto de patrimonio geológico es importante destacar la realización de trabajos y proyectos que rescatan al patrimonio de origen minero. Entre ellos, el vinculado a las posibilidades de desarrollo de un turismo sustentable basado en el patrimonio geológico-minero e industrial en la región sudeste de la provincia de Buenos Aires (Fernández \& Ramos 2007), donde la enorme disponibilidad de rocas de aplicación, posibilitó el desarrollo de una actividad minera pujante. Trabajos posteriores condujeron a propuestas para la creación de rutas turísticas y para la dinamización de espacios basados en el patrimonio geológico-minero del Sistema de Tandilla (Fernández et al. 2008). Hoy en día, una importante área de Tandil que incluye las sierras como recurso natural y con potencial turístico está declarada como paisaje protegido (Ley Provincial 14.126, marzo de 2010, Congreso de la Provincia de Buenos Aires). Esto promovió trabajos de inventario (localización y evaluación del estado actual) de áreas con pasivos ambientales mineros en la localidad de Tandil que permitieron su valorización y el análisis de su inserción territorial y valor patrimonial como parte de una alternativa de uso recreativo sostenible (Fernández et al. 2012).

Otras propuestas han tratado el tema de las oportunidades y obstáculos para transformar el patrimonio geológico-minero en productos turísticos en diferentes provincias del país -particularmente donde la actividad minera ha desaparecido- las políticas orientadas al turismo minero y su potencialidad para incrementar las posibilidades de estas regiones (Fernández et al. 2009). Una de estas iniciativas fue el denominado Programa Nacional de Turismo Geológico Minero (2001/2002), convenio entre el Ministerio de Turismo y la Secretaria de Minería de la Nación, cuyo fin fue el de promover los sitios que por sus características geológico - mineras pudiesen atraer el interés y generar ingresos económicos a través de la actividad turística.

Acciones similares y más recientes ha tomado la provincia de Catamarca a través de su Secretaría de Turismo provincial. Esta dependencia se encuentra estudiando las factibilidades para la creación de un circuito de turismo minero en la zona, no sólo con el 
objetivo de difundir la actividad minera y mejorar la actividad y oferta turística catamarqueña, sino también pensando en los posibles beneficios que estos circuitos brinden a las comunidades aledañas a las minas. La idea es comenzar con experiencias piloto y entre las áreas bajo consideración se encuentran el complejo Muschaca, en Andalgalá, las ruinas de las minas de oro de Incahuasi (Monumento Histórico Nacional, Decreto N 16.482 del 17/12/1943) ubicadas en Antofagasta de la Sierra, y otras como Yampa, Farallón Negro y la Alumbrera (Diarios "Andalgala Hoy", Catamarca, 12/10/12 y La Unión Digital", Catamarca, 13/09/12).

Existen otros varios emprendimientos en los que el patrimonio minero es parte fundamental de la propuesta turística y del patrimonio del lugar, entre ellos Mina La Carolina, en la provincia de San Luis, el famoso cablecarril de la mina la Mejicana en la provincia de la Rioja (Figura 4) declarado Monumento Histórico Nacional por decreto № 999 del 25/10/1982 (Marcos 2008) o las geodas de Minas de Wanda-Libertad, en la provincia de Misiones (Ávila et al. 2008) sólo para mencionar algunos.

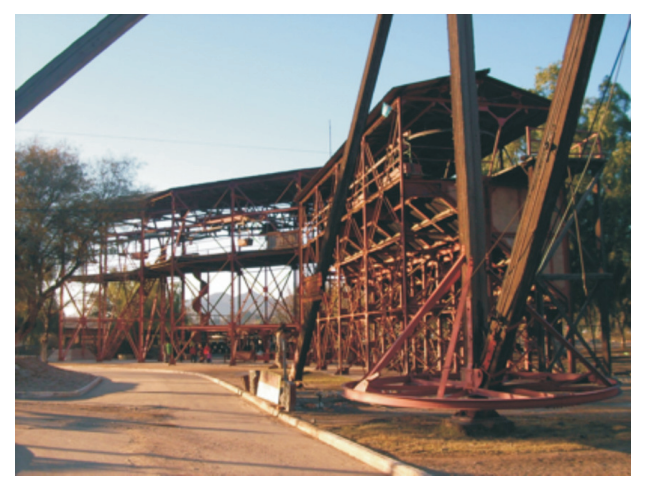

Figura 4 - Estación № 1 del Cablecarril de la mina La Mejicana en Chilecito. Allí el museo "Dr. Santiago Bazán" exhibe maquinarias, herramientas y elementos diversos utilizados en la época de funcionamiento del cable (Fotografía por Fernando Miranda).

\section{LOS PARQUES GEOLÓGICOS Y LOS GEOPARQUES}

Otra de las modalidades en la conservación y valoración del patrimonio geológico es la que aborda el concepto de parques geológicos y geoparques. Argentina cuenta con varios parques geológicos o reservas que contemplan, principalmente, contenidos paleontológicos, pero también geológicos y mineros. Si bien no se trata de geoparques miembros de la Red Global de Geoparques (GGN) amparados bajo la tutela de la UNESCO, comparten objetivos similares: conservación, educación y desarrollo sustentable.

El Geoparque Bryn Gwyn (que en galés significa "Loma Blanca") se localiza en el noreste de la provincia del Chubut, sobre la margen sur del río homónimo y a 8 kilómetros de la localidad de Gaiman. El origen de esta reserva natural de más de 250 hectáreas se remonta a 1993, siendo la primera en su tipo de toda Sudamérica. Operado por el Museo Paleontológico Egidio Feruglio (MEF) con sede en Trelew, el geoparque ofrece un recorrido por el pasado natural de este rincón de la Patagonia. Allí se pueden observar fósiles parcialmente expuestos (Figura 5) testigos de una historia de cambios geológicos y climáticos que afectaron la región durante los últimos 40 millones de años, desde mediados del periodo Paleógeno a la actualidad. El geoparque ofrece excursiones diurnas y nocturnas, con guías profesionales y programas vinculados a paleontología, botánica y astronomía (Cúneo 2008).

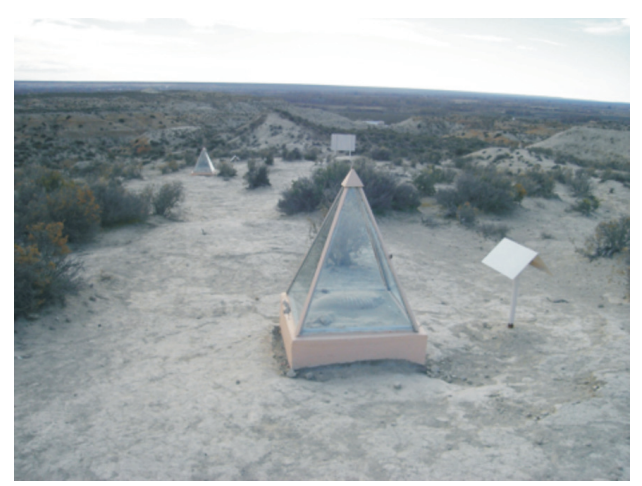

Figura 5 - Protecciones vidriadas en los sitios con restos fósiles (Fotografía Fernando Miranda).

El Parque Geológico Sanagasta, en la provincia de La Rioja, fue creado por decreto № 115 del 7 de Marzo del 2001 y ratificado por Ley Provincial № 7093. Se trata de un área de poco más de 800 hectáreas ubicada próxima a la Villa Sanagasta. El hallazgo de un gran número de nidos y abundantes cáscaras de huevos de dinosaurios significó un cambio en el esquema geocronológico de la región, trasladando al Cretácico Superior estratos considerados hasta entonces terciarios (Hünicken 2005, Tauber 2007). Debido a las excelentes exposiciones de rocas graníticas del basamento y de la secuencia sedimentaria, con buenos contactos y contrastes de colores que hacen de la geomorfología un recurso paisajístico, se propuso al Gobierno de la Provincia de La Rioja la creación del Parque Geológico Sanagasta. El Decreto de creación adjudica al Centro Regional de Investigaciones Científicas y Transferencia Tecnológica (CRILAR) el control científico y académico de este parque geológico. El parque ha tomado gran impulso durante estos últimos años, convirtiéndose en un gran atractivo desde el punto de vista ambiental, ecológico, educativo y turístico.

La Reserva natural Divisadero Largo, en la provincia de Mendoza, comprende 492 hectáreas, ubicadas en el pedemonte de la precordillera, 8 kilómetros al oeste de la ciudad de Mendoza, capital de la provincia. Fue declarada Área Protegida en 1983 y su 
nombre hace referencia al Cerro Divisadero, desde el cual los nativos avistaban el tránsito de las manadas de guanacos y otros animales para darles cacería. Más allá de la belleza natural del área, se destaca en la Reserva una evidente falla geológica cuyo desplazamiento ha permitido el afloramiento de diferentes niveles de rocas sedimentarias que representan un intervalo de tiempo mayor de $\mathbf{2 0 0}$ millones de años. El principal propósito de la creación de la Reserva lo constituye la protección del conjunto de afloramientos de rocas sedimentarias fosilíferas (Figura 6).

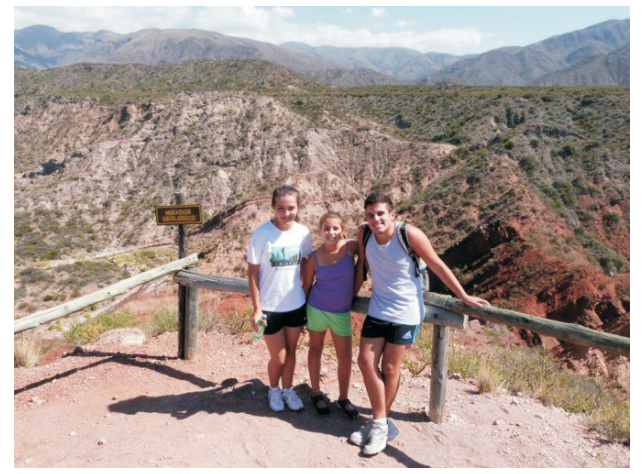

Figura 6 - Panorama desde el Mirador Geológico de la Reserva Natural Divisadero Largo (Fotografía por Cecilia Iglesias).

La provincia de Neuquén ha adquirido gran significado a nivel paleontológico debido a sus numerosos e importantes hallazgos de sitios fosilíferos y por esta razón hoy se la conoce como "Tierra de Dinosaurios". El Centro Paleontológico Lago Barreales (CePaLB), comprende un yacimiento que posee gran cantidad de restos fósiles del período Cretácico: peces, plantas, tortugas, cocodrilos, pterosaurios, dinosaurios herbívoros de diversos grupos y dinosaurios carnívoros como Unenlagia paynemili y Megaraptor namunhuaiquii. En síntesis un ecosistema casi completo de un lapso de la Era Mesozoica. El Centro (Figura 7) depende de la Universidad Nacional del Comahue, que resguarda esta pequeña parte del suelo neuquino. Con el apoyo de empresas y del gobierno provincial, se cuenta con instalaciones adecuadas, que garantizan tanto la protección del patrimonio natural y cultural del área, como las condiciones de seguridad del equipo de trabajo permanente, de los estudiantes y del público visitante.

El sitio ha tomado trascendencia internacional ya que se ha convertido en la única excavación de dinosaurios en el mundo, abierta al público todo el año. El CePaLB tiene como finalidad la educación en geología y paleontología a través de las vivencias personales que obtienen los visitantes en las excavaciones, senderos interpretativos y miradores panorámicos, así como en las visitas al centro de interpretación con proyección de videos, a la sala de exhibición paleontológica con servicio de guías y al laboratorio, donde el visitante puede interiorizarse de las técnicas de trabajo para la preparación de piezas fósiles para su exposición (Calvo et al. 2008).

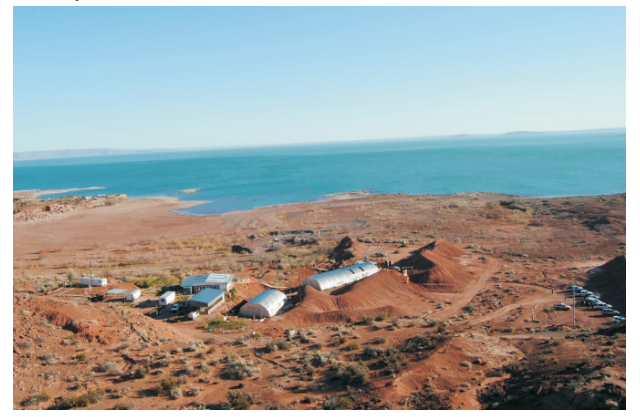

Figura 7 - El Centro se encuentra enmarcado por un paisaje natural en el que se desarrollan actividades educativas y culturales para todos los grupos que visitan el sitio, para todos los niveles, incluso el universitario. Se muestran todas las etapas en el rescate de restos de dinosaurios, desde la extracción hasta su estudio científico final y puesta en exhibición de las piezas rescatadas (Fotografía Jorge Calvo).

También cabe destacar acciones tendientes a la preservación del patrimonio a través de la interacción entre el Estado y la actividad privada. Un ejemplo de ello es el de la protección y puesta en valor turístico del Bosque Petrificado "Florentino Ameghino" bajo la figura jurídica de Custodio Rural (Lech \& Reinoso 2008, Reinoso \& Lech 2010). Esta área situada en el valle inferior del Río Chubut, departamento Gaiman, provincia del Chubut, es un recurso natural no renovable y al mismo tiempo un objeto del patrimonio cultural-paleontológico. La experiencia en esta área concilia actividades científicoacadémicas, de protección patrimonial, empresarialturística privada, junto a un programa de actividades educativas. El plan de manejo contempla aporte científico, desarrollo turístico, inversión empresarial privada en infraestructura y servicios y, sobre todo, la coordinación y contralor del Estado como el responsable primario de la preservación del patrimonio. El Bosque Petrificado "Florentino Ameghino" (Figura 8) se encuentra en un terreno privado, con los derechos inalienables que ello conlleva; no obstante el dominio de ese elemento patrimonial es exclusivo del Estado Provincial.

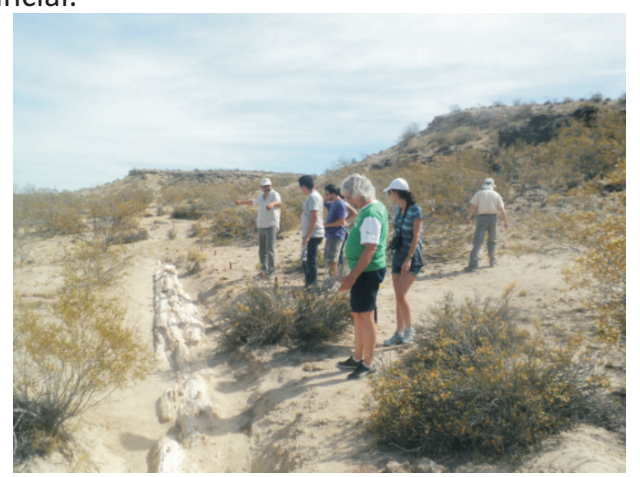

Figura 8 - El Bosque petrificado "Florentino Ameghino" es el primer Custodio Rural de la Provincia del Chubut y único en la República. El Bosque forma parte de la Formación Salamanca, y los troncos petrificados corresponderían a árboles que formaban parte de un extenso bosque de lauráceas y fagáceas que existió hace 60 millones de años. 
La Reserva Natural Pehuen Co-Monte Hermoso, en la costa atlántica del sudeste de la provincia de Buenos Aires, alberga, en una extensión de más de 3 kilómetros a lo largo de la playa, rocas sedimentarias del Pleistoceno tardío en las que se pueden observar numerosas huellas fósiles. Se trata de un yacimiento paleoicnológico donde se conservan pisadas de fauna y megafauna (megaterios y gliptodontes) de 12.000 años de antigüedad. La cantidad y calidad de improntas fósiles lo convierten en un lugar único. En el área de la Reserva se encuentra a su vez uno de los dos puntos de mayor importancia paleontológica descubiertos por Darwin en el transcurso de su viaje a bordo del Beagle (1832 y 1833), la Barranca Monte Hermoso. Otro de los sectores de la Reserva conserva el testimonio de huellas de aborígenes de 7.000 años de antigüedad. En diciembre de 2005, la Cámara de Diputados de la provincia de Buenos Aires promulgó la ley 13.394 que lo declara Reserva Geológica y Paleontológica Provincial, aunque aún no ha sido reglamentada ni puesta en práctica (Manera, 2008).

\section{EL PROYECTO SITIOS DE INTERÉS GEOLÓGICO DE LA REPÚBLICA ARGENTINA}

El Servicio Geológico Minero Argentino (SEGEMAR) es el organismo a quien incumbe, entre otras funciones, el relevamiento geológico y temático del Territorio Nacional, aportando la investigación de base necesaria para el desarrollo productivo, y debiendo atender asimismo a la difusión de sus resultados y a la protección del patrimonio natural. En este escenario, y consciente de la importancia que tiene la identificación de los Sitios de Interés Geológico (SIG), el SEGEMAR inició a fines del año 2004 -en oportunidad de conmemorar 100 años de su creación -el proyecto Sitios de Interés Geológico de la República Argentina. A fin de alcanzar algunos de sus objetivos y llevar a cabo otras tareas especificas, el Instituto de Geología y Recursos Minerales (IGRM) del SEGEMAR creó el Grupo de Trabajo de Sitios de Interés Geológico, cuya función es dar a conocer a la comunidad en general los sitios de interés geológico, difundir el conocimiento geológico y brindar información que sirva de base para la realización de otras actividades vinculadas con el medio natural (Lema \& grupo CSIGA, 2007).

El proyecto se orientó fundamentalmente a satisfacer una demanda cada vez más creciente del público en general, proporcionando datos, características y explicaciones que en forma comprensible permitan al público acceder al conocimiento geológico de áreas emblemáticas del país. Para una mejor valoración y comprensión del patrimonio, este proyecto requirió del trabajo conjunto con instituciones locales, provinciales y municipales, constituyéndose de este modo en una fuente de información útil para pobladores, escuelas y organizaciones vinculadas al turismo.

\section{ALgUNAS ACCIONES DE DIVULGACIÓN DEL PATRIMONIO GEOLÓGICO}

En una primera etapa el Grupo de Trabajo se abocó a la edición del libro "Sitios de interés geológico de la República Argentina, los geólogos nos cuentan..." (CSIGA 2008). Esta publicación fue el resultado del esfuerzo conjunto del SEGEMAR y más de 120 autores representantes de 40 instituciones públicas y privadas, así como de organizaciones no gubernamentales. La obra se organizó en dos volúmenes que corresponden al norte y sur del país y se ocupa de los "cómo, cuándo y por qué" de 72 sitios de interés - entre los que se incluyen lugares famosos por sus paisajes - y en los que se tratan diversos temas tales como vulcanismo, geomorfología, paleontología, hidrogeología, tectónica, peligrosidad geológica y estratigrafía, entre otros.

Los capítulos fueron editados por la Comisión de Sitios de Interés Geológico de la República Argentina (CSIGA) con el objeto de llegar a un público no especializado, por lo que cada sitio está descrito con lenguaje ameno e ilustrado con mapas, fotografías, esquemas y cuadros cronológicos que facilitan la comprensión de los diferentes procesos y temas geológicos. Algunos capítulos sugieren medidas de protección y, donde éstas ya están en vigencia, otras nuevas son puestas a consideración.

Las conexiones entre geología y antropología, así como referencias históricas sobre la actividad minera y las exploraciones e investigaciones científicas pioneras, enriquecen algunos de los capítulos, además de menciones especiales sobre flora y fauna. Al especial interés geológico de la gran mayoría de los SIG escogidos, se contempló la accesibilidad, buen estado de preservación y gran belleza y expresividad escénica. Los volúmenes están escritos en idioma español y cada sitio cuenta con un breve resumen introductorio en inglés. La obra tiene el propósito de difundir el conocimiento geológico, contribuir a la transmisión del pensamiento científico y estimular actividades educativas, y de esta manera promover la protección del patrimonio (Miranda \& grupo CSIGA, 2009, 2010; Echeverría et al. 2010).

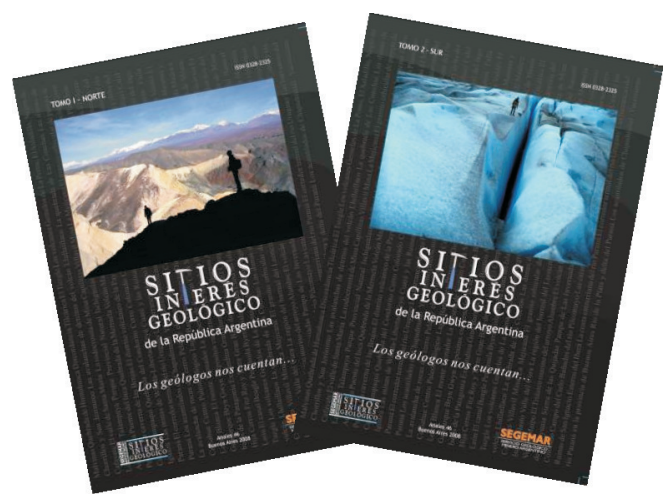

Figura 9 - Sitios de Interés Geológico de la República Argentina. Volumen I (Norte) y Volumen II (Sur). 
Tanto el proyecto, como la obra, han sido galardonados con sendos premios: el VII premio Convenio Andrés Bello "Somos Patrimonio" en el año 2008 y el Premio Especial Bicentenario otorgado en 2010 por Gaea, Sociedad de Estudios Geográficos de la República Argentina en virtud del carácter divulgativo de la obra.

Para el público en general, el patrimonio geológico y la geología como ciencia son muy poco conocidos, a pesar de las interrelaciones entre el entorno geológico, los demás elementos del ecosistema y el medio socio-cultural. Sin embargo, en estas últimas décadas, el interés por los aspectos geológicos del territorio muestra un marcado crecimiento (Voth 2008). Teniendo en cuenta esta consideración y con el objetivo de identificar actividades e inquietudes de los lectores y potenciales interesados en la temática de la publicación, y a fin de establecer futuras líneas de trabajo, se procedió a la elaboración de una breve encuesta permanente en la que se consultaba acerca del motivo de interés en el libro (Miranda 2011). Sin ponderar a aquellos profesionales vinculados específicamente con las Ciencias Geológicas, los resultados arrojaron que la población interesada correspondía a personas con estudios universitarios completos o en curso y de variadas profesiones: administración, agronomía, biología, comunicación social, contabilidad, docencia, geografía, guardaparques, informática, ingeniería, medicina y turismo. También se recibieron consultas por parte de estudiantes, tiendas de venta de libros y puestos de regalos o recuerdos en museos, ONGs y fundaciones.

Por los intereses e inquietudes planteados puede señalarse que: el 31 \% se vinculaba con el área de educación; al turismo le correspondió el 14\%: agencias u operadores, y particulares que manifestaron su deseo de conocer más sobre los lugares que visitarían o habían visitado; un 15 \% lo requirió como material de consulta: solicitudes de bibliotecas, fundaciones, organizaciones no gubernamentales y otras instituciones; el 8\% para cultura general -interés por las áreas naturales o por las ciencias geológicas; un 7\% agrupó a quienes consultaron por la posibilidad de reventa, tanto en tiendas comerciales como en tiendas de museos y el $1 \%$ correspondió a otros motivos. Un $23 \%$ no respondió la encuesta, pero de los datos recabados surgió claramente la fuerte atracción que en general despiertan los temas geológicos.

La divulgación científica admite muy variadas formas, tales como conferencias, muestras, museos interactivos, charlas, libros, revistas y folletos, entre otros (Gallardo 2005). Muchas son las personas que visitan un área en particular atraídas por su paisaje. Allí, la información a través de paneles temáticos in situ de aquello que se contempla en forma directa resulta de gran efectividad y una buena oportunidad de acercar al público en general a aspectos concernientes a las ciencias de la Tierra.
En este sentido, en enero de 2007, se realizó una experiencia piloto (Figura 10) en la Reserva Natural Laguna Diamante, provincia de Mendoza, que contó con financiamiento privado y estatal (Miranda \& Sáenz 2008). El área en cuestión se encuentra a unos 3.500 metros de altura sobre el nivel del mar en la cordillera de los Andes y a escasos kilómetros del límite argentino-chileno. A pesar del difícil acceso, el área recibe durante la temporada estival numerosos visitantes, locales y extranjeros, que desarrollan diferentes actividades, entre ellas, pesca deportiva, andinismo o "simplemente" turismo. Si bien la reserva contaba en su haber con cuantiosa información sobre flora y fauna, aquella relacionada a la geología del área y al paisaje -que es lo que el público percibe en forma instantánea- resultaba escasa o confusa. En el ámbito de la reserva se destaca la imponente figura del Volcán Maipo, de 5.323 metros de altura, inmerso en una estructura oval de 20 por 16 kilómetros denominada Caldera Diamante, cuyas paredes, constituidas por rocas sedimentarias y volcánicas más antiguas, rodean al volcán. La historia más "reciente" del área, científicamente documentada (Sruoga et al. 2005), se remonta a la súbita erupción de unos 350 kilómetros cúbicos de cenizas incandescentes o ignimbritas unos 450.000 años atrás. Esto y el posterior desarrollo del volcán Maipo durante los últimos 100.000 años, permiten acercar al público en general a uno de los aspectos más espectaculares de las ciencias de la Tierra, el volcanismo.

El éxito de esta primera prueba indujo a continuar con la tarea en otros lugares del país

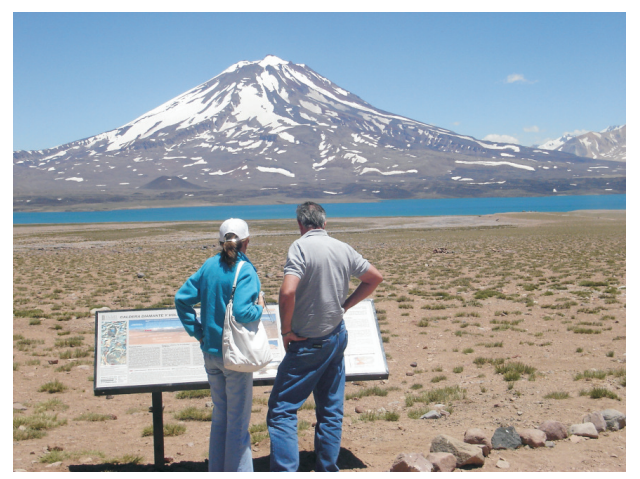

Figura 10 - El cartel, de 200 por 70 centímetros, consta de un texto principal en el que se describen los estadios evolutivos del centro eruptivo volcán Maipo - caldera del Diamante, textos secundarios vinculados al paisaje actual, historia eruptiva y peligrosidad, vistas panorámicas explicativas y fotografías de diferentes sectores del área, imagen satelital y texto resumido en inglés. 
La ejecución de los paneles, financiados con fondos otorgados por el Convenio Andrés Bello (Miranda y grupo CSIGA 2009) está a cargo de la Comisión de Sitios de Interés Geológico de Argentina del SEGEMAR. La tarea comienza con sitios propuestos por los potenciales interesados (Municipio, ONG's, etc), que en la medida de las posibilidades, son examinados en el terreno para evaluar su interés geológico, accesibilidad, infraestructura disponible (prevención de actos vandálicos) y ubicación espacial para el diseño de los paneles. Atendiendo a las sugerencias y necesidades de los receptores locales, los temas son seleccionados y presentados con el soporte de artículos científicos actualizados y con la participación activa de profesionales que desarrollan tareas en el área, garantizando un óptimo nivel de información.

Trabajos de esta índole se han realizado en la Reserva Natural Urbana General San Martín en la provincia de Córdoba (Gaido et al. 2010); en La Reserva Natural Urbana Parque del Este, Baradero y en diferentes áreas de San Pedro, ambas localidades de la provincia de Buenos Aires (Voglino 2008, Miranda et al. 2011); en el área del Monumento Histórico Nacional y Patrimonio Cultural de la Humanidad de la UNESCO (1999) Cueva de las Manos, en la provincia de Santa Cruz (Geuna \& Escosteguy 2008), en el Parque provincial Aconcagua en la Provincia de Mendoza (Cegarra y Ramos 2008); en el área del Lago Buenos Aires, localidad de Los Antiguos, provincia de Santa Cruz (Escosteguy \& Geuna 2008), y se proyecta continuar con estas tareas en el ámbito de Parques Nacionales, por ejemplo en el parque Nacional Monte León en la Provincia de Santa Cruz (Sacomani et al. 2008). Todos estos paneles abordan los contenidos geológicos que el visitante puede contemplar (Figuras 11 a 18).

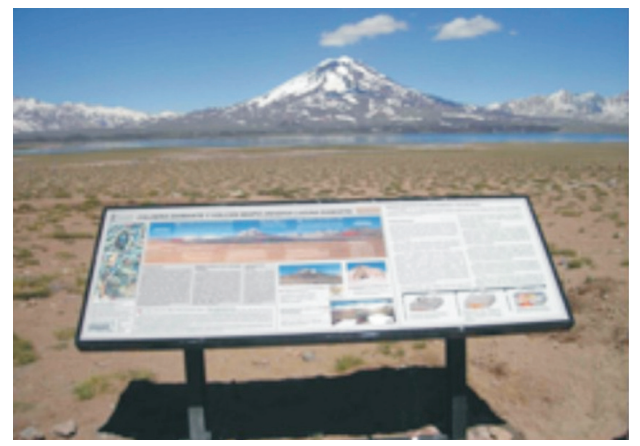

Figura 11 - Paneles temáticos instalados en el marco del proyecto Sitios de Interés Geológico del SEGEMAR. Reserva Natural Laguna del Diamante, provincia de Mendoza.

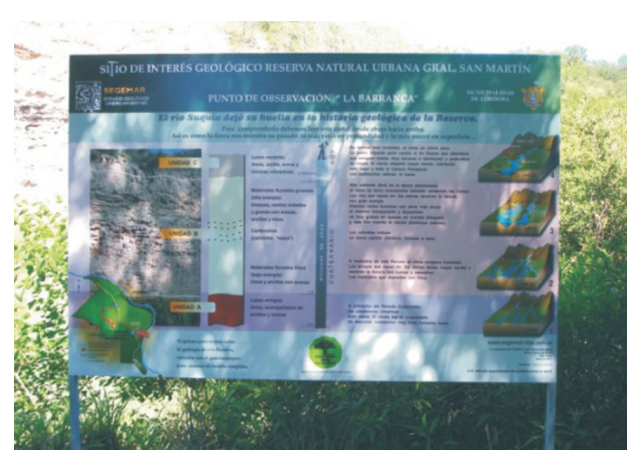

Figura 12 - Paneles temáticos instalados en el marco del proyecto Sitios de Interés Geológico del SEGEMAR. Reserva Natural Urbana Geral. San Martin, provincia de Córdoba.

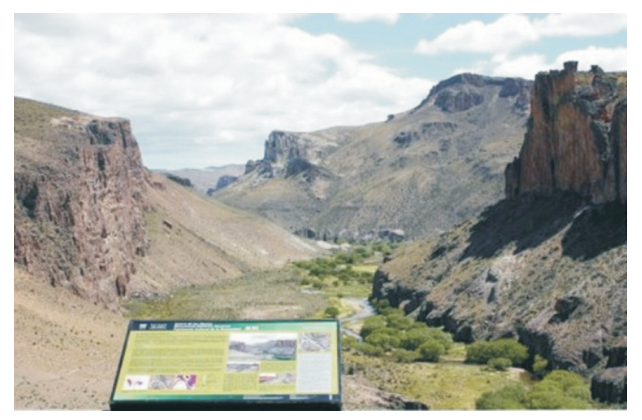

Figura 13 - Paneles temáticos instalados en el marco del proyecto Sitios de Interés Geológico del SEGEMAR. Monumento Histórico Nacional y Patrimonio de la Humanidad. Cueva de Las Manos, provincia de Santa Cruz.

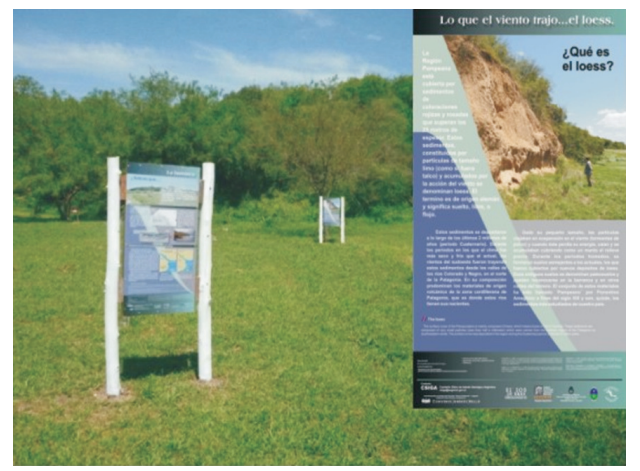

Figura 14 - Paneles temáticos instalados en el marco del proyecto Sitios de Interés Geológico del SEGEMAR. Reserva Natural Urbana Parque del Este, provincia de Buenos Aires. 


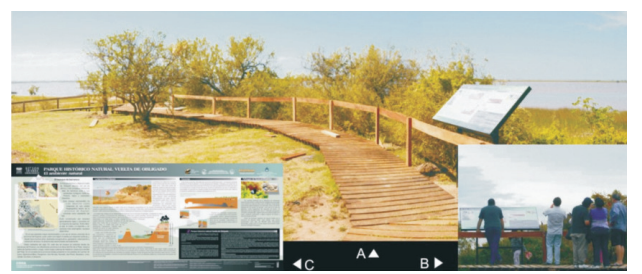

Figura 15 - Paneles temáticos instalados en el marco del proyecto Sitios de Interés Geológico del SEGEMAR. Reserva Natural Vuelta de Obligado, provincia de Buenos Aires.

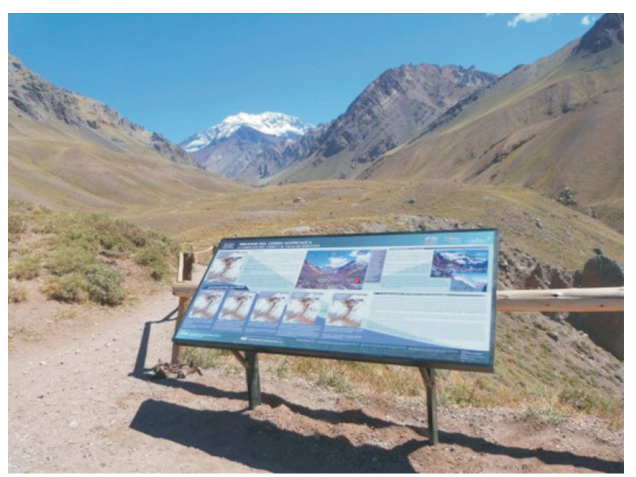

Figura 16 - Paneles temáticos instalados en el marco del proyecto Sitios de Interés Geológico del SEGEMAR. Parque Provincial Aconcagua, provincia de Mendoza.

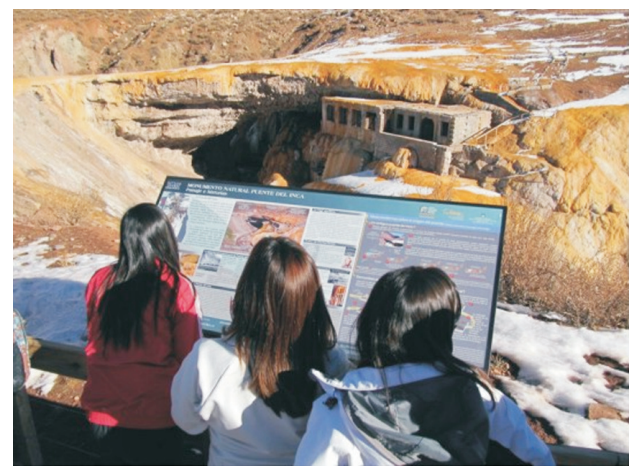

Figura 17 - Paneles temáticos instalados en el marco del proyecto Sitios de Interés Geológico del SEGEMAR. Puente del Inca, provincia de Mendoza.

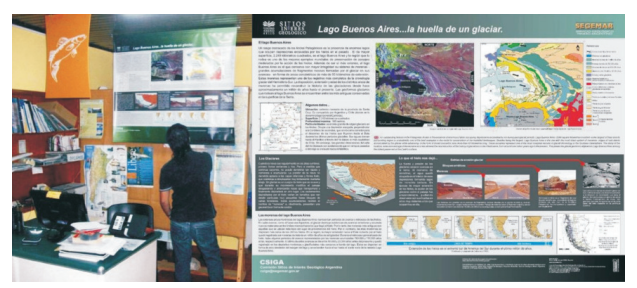

Figura 18 - Paneles temáticos instalados en el marco del proyecto Sitios de Interés Geológico del SEGEMAR. Los Antiguos, provincia de Santa Cruz.

Durante el año 2012 otras acciones relacionadas con paneles temáticos -desde otros organismos- fueron la puesta en valor del patrimonio paisajístico y la implementación de miradores interpretativos en la provincia de Jujuy. Esto fue llevado a cabo a través de un Programa Nacional de Inversiones Turísticas y de Señalización Turística de la Provincia de Jujuy, encarado por la Secretaría de Turismo y Cultura de la provincia con el apoyo del Ministerio de Turismo de La Nación. Los miradores y los paneles (Figura 19) brindan información sobre paisajes icónicos de la provincia y muestran en muchos casos una breve descripción de las formaciones geológicas, con textos en idioma español, inglés y portugués. Están ubicados a la vera de rutas nacionales y provinciales. Entre los puntos seleccionados se encuentran las Salinas Grandes, la Cuesta de Lipán, la Paleta del Pintor, las Huellas de Dinosaurios, las Termas de Reyes, el Dique La Ciénaga, la Laguna Desaguadero (en Yala) y el Parque Nacional Calilegua.

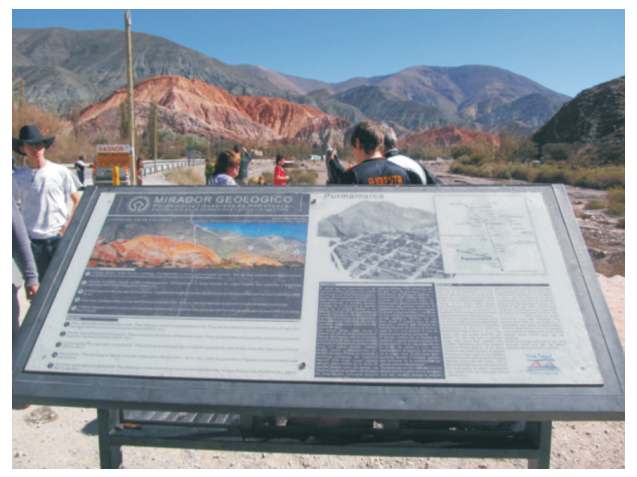

Figura 19 - El primer mirador geológico de Jujuy fue habilitado en la localidad de Purmamarca, con vista al Cerro Siete Colores (Fotografía por Fernando Miranda). 


\section{REFLEXIONES FINALES}

El concepto de patrimonio geológico es relativamente nuevo en nuestro país. No obstante, de los párrafos anteriores se desprende que no han sido ni son pocos los profesionales e instituciones interesados en la materia. Cabe aclarar aquí que solo hemos hecho mención de algunas acciones, siendo conscientes de la existencia de trabajos vinculados al tema en otras diferentes áreas del país.

Sin embargo, más allá de los muchos esfuerzos individuales se torna necesario un trabajo conjunto y con continuidad en el tiempo. Es entonces cuando surgen cuestiones acerca de ¿Cómo lograr éxito en el desarrollo de los programas, especialmente cuando muchas veces los recursos económicos no son los adecuados? ¿Cómo evitar la superposición de tareas a nivel de Instituciones? ¿De qué manera conservar el entusiasmo de proyectos que se inician?...

Cada pregunta tendrá su particular respuesta, pero sin duda hay premisas fundamentales que cumplir, y las siguientes son algunas:

1) Inventario, catalogación y confección de un listado sistemático de los bienes que integran el patrimonio geológico, a escala local, provincial o regional y nacional.

2) Designación de un organismo de nivel nacional que sea referente y a la vez formador en el tema, encargado de articular el accionar de los distintos actores intervinientes.

3) Formulación de una política de divulgación y protección del patrimonio geológico, con adjudicación de recursos adecuados.
4) Continuidad de los programas en el tiempo.

La identificación, descripción, divulgación y protección del patrimonio geológico es de vital importancia pues su degradación casi siempre es irreversible. Los sitios de interés geológico deben ser considerados como un elemento más del patrimonio, e incluidos en una correcta gestión del territorio, puesto que, siendo los sitios construcciones naturales, desde el momento en que se los conceptualiza y se brinda conocimiento sobre ellos se transforman en una parte fundamental del patrimonio natural y cultural de las personas, paso indispensable para promover a su protección.

Debe insistirse en que el patrimonio geológico abarca múltiples aspectos que a menudo se olvidan. Como ejemplo vaya el resguardo y mantenimiento de colecciones centenarias de rocas, minerales y fósiles que han soportado décadas de abandono.

Dada su particularidad, es necesario evaluar - en el contexto de normas generales - medidas de protección concretas para el patrimonio geológico, entendiendo como parte de esto el desarrollo de legislación específica.

En la actualidad, tanto los destinos turísticos más conocidos como aquellos menos tradicionales, pero que también son visitados por gran cantidad de personas, requieren como valor agregado la información geológica como parte de las actividades recreativas y turísticas que promueven la apreciación del medio natural. Estos paisajes son inmejorables aliados para introducir a terceros en el tema del patrimonio geológico.

Los resultados de cualquier estrategia de prevención sólo se ven a largo plazo; el tiempo urge y se debe asumir esta tarea como un compromiso.

\section{Referencias}

AGUIRRE Urreta, M. B., RAMOS, V. A. 1996. Áreas de Interés. En: Ramos, V. A. (Ed.): Geología de la Región del Aconcagua. Provincias de San Juan y Mendoza, República Argentina. Dirección Nacional del Servicio Geológico, Subsecretaría de Minería de La Nación. Anales 24 (18): 471-480. Buenos Aires.

ARDOLINO A., BUSTEROS, A., LEMA H. 2002. Sitios de Interés Geológico. En Haller M. (Ed.) Relatorio del XV Congreso Geológico Argentino, VI-2: 1-18p El Calafate.

ÁVILA F.M., CRIVELLO J.F., PORTANERI J.G. 2008. Las minas de Wanda-Libertad. Piedras preciosas en Misiones. En: CSIGA (Ed.) Sitios de Interés Geológico de la República Argentina. Instituto de Geología y Recursos Minerales. Servicio Geológico Minero Argentino, Anales 46, I, Buenos Aires, 391-400p.
BARALDO J., MONETTA A, CARDINALI, A., WEIDMANN R., CONTRERAS V. 2005. Los Sitios de interés geológico de la Provincia de San Juan. Actas del XVI Congreso Geológico Argentino, 5: 427-432, La Plata.

BARRIENTOS Ginés A.V., MOYA M.C. 2011. La Reserva Natural Cerro San Bernardo. XVIII Congreso Geológico Argentino, Neuquén. Actas (CD).

BERTOLINI J., BAHLER G., ZABALEGUI F. 2005. Sitios de interés geológico de Entre Ríos. Actas del XVI Congreso Geológico Argentino, 5: 433-436, La Plata.

BRANDÁN E.M., VIERA V.O., BOSO M.A. 2011. Riesgo geológico en el Sitio Arqueológico Nacional Incahuasi de la provincia de Salta. XVIII Congreso Geológico Argentino, Neuquén Actas (CD). 
CALVO J.O., SÁNCHEZ M.L., HEREDIA S., PORFIRI J.D. 2008. Centro paleontológico Lago los BarrealesProyecto Dino, Neuquén. Un ecosistema del Cretácico Superior. En: CSIGA (Ed.) Sitios de Interés Geológico de la República Argentina. Instituto de Geología y Recursos Minerales. Servicio Geológico Minero Argentino, Anales 46, II, Buenos Aires, 577$592 \mathrm{p}$.

CANTERO J.J., SFRAGULLA J., NÚÑEZ C., BONALUMI A., MULKO J., AMUCHASTEGUI A., BARBOZA G., ARIZA Espinar L., CHIARINI F., 2011. Flora de los afloramientos de mármoles y serpentinitas de las sierras de Córdoba. XVIII Congreso Geológico Argentino, Neuquén Actas (CD).

CASELLI A.T. 2002. Contexto Geológico del Parque Nacional Talampaya: Desarrollo y potencialidad. En: Cabaleri N., Cingolani C.A., Linares E., López de Luchi M.G., Ostera H., Panarello H.O. (Eds) XV Congreso Geológico Argentino. Calafate, Santa Cruz, Actas (CD).

CASELLI A.T. 2008. Talampaya. Viento, agua y tiempo, diseñadores de una arquitectura deslumbrante. En: CSIGA (Ed.) Sitios de Interés Geológico de la República Argentina. Instituto de Geología y Recursos Minerales. Servicio Geológico Minero Argentino, Anales 46, I, Buenos Aires, 131-144 p.

CEGARRA M., RAMOS. V. 2008. Cerro Aconcagua. La cumbre más alta de América. En: CSIGA (Ed.) Sitios de Interés Geológico de la República Argentina. Instituto de Geología y Recursos Minerales. Servicio Geológico Minero Argentino, Anales 46, I, Buenos Aires, 189$202 p$.

CINGOLANI C. A. 2008. Tandilia. Las rocas y los fósiles más antiguos de Argentina. En: CSIGA (Ed.) Sitios de Interés Geológico de la República Argentina. Instituto de Geología y Recursos Minerales. Servicio Geológico Minero Argentino, Anales 46, II, Buenos Aires, 477$494 p$

CSIGA (Ed). 2008. Sitios de Interés Geológico de la República Argentina. Los geólogos nos cuentan. Instituto de Geología y Recursos Minerales, Servicio Geológico Minero Argentino, Anales 46, Tomos 1 y 2. 907.p Buenos Aires, Argentina.

CÚNEO N. R. 2008. El Geoparque Bryn Gwyn. 40 millones de años atrás en la Patagonia. En: CSIGA (Ed.) Sitios de Interés Geológico de la República Argentina. Instituto de Geología y Recursos Minerales. Servicio Geológico Minero Argentino, Anales 46, II, Buenos Aires, 697$704 p$.

DANIELI J.C., CARBONE O., FRANCHINI M., GARRIDO A., GINGINS M., LEANZA H. 2011. Sitios de Interés Geológico. En: Leanza H., Arregui C., Carbone O., Danieli J., Vallés J.M. Relatorio de XVII Congreso Geológico Argentino. Geología y recursos naturales de la provincia de Neuquén.. 881-893 p.
ENDERE M. L., PODGORNY I. 1997. Los Gliptodontes son argentinos. La ley 9080 y la creación del Patrimonio Nacional. Ciencia Hoy. Revista de Divulgación Científica y Tecnológica de la Asociación Ciencia Hoy. Volumen 7 - №42 - Set/Oct 1997

ERMILI R., MARTINEZ A. 2011. Propuesta geoturística en San Rafael-Los Reyunos, provincia de Mendoza, Argentina. XVIII Congreso Geológico Argentino, Neuquén Actas (CD).

ESCOSTEGUY L.D., GEUNA S.E. 2008. Lago Buenos Aires. La huella de un glaciar. En: CSIGA (Ed.) Sitios de Interés Geológico de la República Argentina. Instituto de Geología y Recursos Minerales. Servicio Geológico Minero Argentino, Anales 46, II, Buenos Aires, 759$770 p$.

ETCHEVERRÍA M., LEMA H., MIRANDA F., ARDOLINO A., ANSELMI A., ECHEVARRÍA. A, FRANCHI M., LAGORIO S., NEGRO, C. 2010. Patrimonio geológico: proyecto Sitios de Interés Geológico de La República Argentina. Simposio "Geoparques, Patrimonio Natural y Cultural", XV Congreso Peruano de Geología. Sociedad Geológica del Perú. Publicación especial N 9. p. 265-268

FERNÁNDEZ G., RAMOS, A. 2007. El patrimonio de los pueblos minero-industriales del sudeste bonaerense (Argentina) como recursos para nuevos productos turísticos. Sociedad Española para la Defensa del Patrimonio Geológico y Minero. De Re Metallica 8, 65-72p.

FERNÁNDEZ G., VALENZUELA S., CASTRONOVO R., RICCI S., ALEJANDRO D., RAMOS A. 2008. El patrimonio geológico-minero como recurso para crear rutas turísticas en el sistema de Tandilia, Argentina. Sociedad Española para la Defensa del Patrimonio Geológico y Minero. De Re Metallica, 10-11, 81-90p.

FERNÁNDEZ G., CASTRONOVO R., VALENZUELA S., RICCI S., RAMOS, G. 2009. Patrimonio geológico-minero y turístico en Argentina. Sociedad Española para la Defensa del Patrimonio Geológico y Minero. De Re Metallica 13, 71-81p.

FERNÁNDEZ G., RICCI S., VALENZUELA S., CASTRONOVO R., RAMOS A. 2012. Patrimonio minero geológico: pasivos ambientales, territorio y usos alternativos. En: Ana Ulberich (Ed.) Estudios Ambientales III: Tandilia y el sudeste bonaerense. Universidad Nacional del Centro de la Provincia de Buenos Aires, $210 \mathrm{p}$.

GAIDO M. F., SAPP M., MIRÓ R.C., SACCHI G. 2010. Circuitos de interpretación geológica en áreas protegidas de la Municipalidad de Córdoba. Sitio de interés geológico Reserva Natural Urbana General San Martín. Segemar 22p.

GALLARDO S. 2005. Los médicos recomiendan. Un estudio de las notas periodísticas sobre salud. Buenos Aires: Editorial Universitaria de Buenos Aires (Eudeba). 214 p. ISBN 950-23-1358-5. 
GEUNA S.E., ESCOSTEGUY L.D. 2008. El Valle del Río Pinturas. La Cueva de las Manos. En: CSIGA (Ed.) Sitios de Interés Geológico de la República Argentina. Instituto de Geología y Recursos Minerales. Servicio Geológico Minero Argentino, Anales 46, II, Buenos Aires, 771-780p.

GOSO C., AMIR K., COLOMBO F., VERÍSSIMO C., AMORÍN B. 2011. Grutas del Palacio: primer patrimonio geológico en Uruguay gestionado como geoparque. XVIII Congreso Geológico Argentino, Neuquén Actas (CD).

GUIDO E.Y., SESMA P. J. 2011. Valorización de la geodiversidad de la provincia de Tucumán: circuito geológico de "El Cadillal". XVIII Congreso Geológico Argentino, Neuquén Actas (CD).

HÜNICKEN M.A. 2005. La Formación Sanagasta y el Parque Geológico (Cretácico Superior) con Nidos y Huevos de Dinosaurios, Valle de Sanagasta, Provincia de La Rioja, Argentina En: Aceñolaza F. G. (Ed.) INSUGEO, Serie Correlación Geológica, 19: 75-82 p.

IBÁÑEZ Palacios G. P., AHUMADA A. L., PÁEZ S. V. 2012. Patrimonio geológico en una región de la Sierra del Aconquija, provincia de Tucumán y Catamarca, Argentina. Revista Pasos. Vol. 10, 75-87p. Disponible en: www.revistapasosonline.com

IBÁÑEZ Palacios G. P., AHUMADA A. L., PÁEZ S. V. 2011. Geositios en la Quebrada del Portugués, una alternativa para divulgar el patrimonio geológico. XVIII Congreso Geológico Argentino, Neuquén Actas (CD).

IPARRAGUIRRE G., OLIVA C. 2011. Manejo del patrimonio geológico y paleontológico para usos turísticos: el caso de un yacimiento paleoicnológico en el Río Negro, provincia de Buenos Aires. XVIII Congreso Geológico Argentino, Neuquén Actas (CD).

KULEMEYER J. 2011. Los objetos de estudio de la geología como representaciones patrimoniales. XVIII Congreso Geológico Argentino, Neuquén Actas (CD).

LACREAU H., SOSA G., OGGIER, F.2002. Nogolí y su patrimonio geológico, provincia de San Luis, Argentina. En: Cabaleri N., Cingolani C.A., Linares E., López de Luchi M.G., Ostera H., Panarello H.O. (Eds) XV Congreso Geológico Argentino. Calafate, Santa Cruz, Actas (CD).

LEMA H., Grupo CSIGA. 2007. Sitios de Interés Geológico de la República Argentina. VI Convención Internacional sobre Medio Ambiente y Desarrollo. V Congreso de Áreas Protegidas. Resúmenes, 125. La Habana; Cuba.

LECH R.R., REINOSO J.R. 2008. Bosque Petrificado "Florentino Ameghino": una posibilidad cierta de interacción entre Estado y actividad privada en la preservación del patrimonio cultural-paleontológico de la Provincia del Chubut. Reunión Anual de Comunicaciones APA. Neuquén. Ameghiniana Suplemento Resúmenes 45 (4): $29 R$.
LEYNAUD F. 2002. Inventario y caracterización de los puntos de interés geológico (PIG) de la provincia de Córdoba. . En: Cabaleri N., Cingolani C.A., Linares E., López de Luchi M.G., Ostera H., Panarello H.O. (Eds) XV Congreso Geológico Argentino. Calafate, Santa Cruz, Actas (CD).

MANERA T., ARAMAYO S.A., ZAVALA C., CAPUTO R.O. 2008. Yacimiento paleoicnológico de Pehuen Co. Un patrimonio natural en peligro. En: CSIGA (Ed.) Sitios de Interés Geológico de la República Argentina. Instituto de Geología y Recursos Minerales. Servicio Geológico Minero Argentino, Anales 46, II, Buenos Aires, 509-520p.

MARCOS O.R. 2008. Mina La Mejicana. El cablecarril: notable obra de ingeniería de los albores del siglo XX. En: CSIGA (Ed.) Sitios de Interés Geológico de la República Argentina. Instituto de Geología y Recursos Minerales. Servicio Geológico Minero Argentino, Anales 46, I, Buenos Aires, 113-124p.

MARTÍNEZ O.R. 2008. Patrimonio geológico. Identificación, valoración y gestión de sitios de interés geológico. Universidad Nacional de La Plata, Facultad de Humanidades y Ciencias de la Educación Geograficando 4, 233-250p.

MEDINA, W.M. 2012. Propuesta metodológica para el inventario del patrimonio geológico de Argentina. Dissertação de Mestrado em Património Geológico e Geoconservação, Universidade do Minho. Portugal $106 \mathrm{p}$.

MIRANDA F., SÁENZ, A.C. 2008. Del cómo, cuándo y porqué del paisaje ante nuestros ojos: divulgar la geología. XVII Congreso Geológico Argentino, Jujuy. Actas. 939-940 p.

MIRANDA F., Grupo CSIGA. 2009. Proyecto Sitios de Interés Geológico de la República Argentina. XII Congreso Geológico Chileno. Santiago, Chile.

MIRANDA F., Grupo CSIGA. 2010. Sitios de Interés Geológico: una nueva tendencia en Argentina. Memoria 1er Seminario Taller Internacional sobre Patrimonio Geológico, Minero y Metalúrgico, Loja, Ecuador, Junio de 2010, 77-82p.

MIRANDA, F., 2011. Los sitios de interés geológico, ¿quién está interesado?. XIV Congreso Latinoamericano de Geología. Bogotá D. C. Colombia, (CD).

MIRANDA F., PEREYRA F., LEMA H., AGUILAR J.L. 2011. Los paneles temáticos como herramienta del geoturismo: el caso de San Pedro, provincia de Buenos Aires, Argentina. I Simposio de Geoparques y Geoturismo en Chile. Melipeuco-Chile (CD).

NEDER L., RÍOS R. 2011. Revalorización del paisaje geológico como patrimonio natural, 2011. XVIII Congreso Geológico Argentino, Neuquén Actas (CD).

RÍOS R., NEDER L. 2011. Termalismo como patrimonio natural y objeto de explotación. 2011. XVIII Congreso Geológico Argentino, Neuquén Actas (CD). 
OJEDA G., LACREU H., SOSA G., GÓMEZ H., DUEÑAS D. 2008. Atlas de recursos geoambientales del Municipio de Juana Koslay, Provincia de San Luis. Universidad Nacional de San Luis.

OJEDA G., LACREU H., SOSA G., GÓMEZ H. 2007. Atlas de recursos geoambientales del Municipio de Potrero de Los Funes, Provincia de San Luis. Universidad Nacional de San Luis.

PRIMO, L. J. 1951. Guía Geológica del Parque Nacional Nahuel Huapi. Ministerio de Obras Públicas de LA Nación. Administración General de Parques Nacionales y Turismo. República Argentina. $40 \mathrm{p}$.

RAMOS, V. A. 1993. Geología y estructura de Puente del Inca y el control tectónico de sus aguas termales. Simposio sobre Puente del Inca. XII Congreso Geológico Argentino y II Congreso de Exploración de Hidrocarburos, Actas V: 8-19 p.

RAMOS, V. A., CEGARRA M., PÉREZ D., MIRANDA F.J. 2008. Puente del Inca: ingeniería natural. En: CSIGA (Ed.) Sitios de Interés Geológico de la República Argentina. Instituto de Geología y Recursos Minerales. Servicio Geológico Minero Argentino, Anales 46, I, Buenos Aires, 203-214 p.

REINOSO J.R., LECH R.R. 2010. El manejo de visitantes en un Área Protegida a través de figura de "Custodio Rural" en la Provincia del Chubut. Congreso Patagónico de Turismo 2010. Trelew - Rawson. Resúmenes CD.

RIMOLDI, V. H. 1993. Puente del Inca. Un monumento natural comprometido. Simposio sobre Puente del Inca. XII Congreso Geológico Argentino y II Congreso de Exploración de Hidrocarburos. Actas V: 1-7 p.

RUBIO, H. A., SANTILLI, C. A., SALOMÓN, M. A. 1993. Puente del Inca: restauración y preservación. Simposio sobre Puente del Inca. XII Congreso Geológico Argentino y II Congreso de Exploración de Hidrocarburos, Actas V: 20-23 p.

SACOMANI L.E., CODIGNOTTO J., PANZA J.L., ERCOLANO B. 2008. Los acantilados marinos de Monte león. Una costa azotada por el mar. En: CSIGA (Ed.) Sitios de Interés Geológico de la República Argentina. Instituto de Geología y Recursos Minerales. Servicio Geológico Minero Argentino, Anales 46, II, Buenos Aires, 839848p.

SAPP M., GAIDO M.F., LEYNAUD F. 2008. Quebrada de la Mermela. Escenario de una colisión. En: CSIGA (Ed.) Sitios de Interés Geológico de la República Argentina. Instituto de Geología y Recursos Minerales. Servicio Geológico Minero Argentino, Anales 46, I, Buenos Aires, 339-348p.

SEGEMAR-IGRM. 1994. Programa Nacional de Cartas Geológicas de la República Argentina. Modelo de carta geológica. Normativa de realización. 62 p.

SEGEMAR-IGRM. 1997. Programa Nacional de Cartas Geológicas de la República Argentina. Modelo de carta geológica. Normativa de realización. Anexo. 10p.
SFRAGULLA, J.A., PERETTI S., BONALUMI, A. 2010. Primer circuito de geoturismo en Córdoba, Argentina. Agencia Córdoba Turismo-Secretaría de Minería del Gobierno de Córdoba. Presentación en Exposición Traslasierra y Noroeste de Córdoba Temporada Otoño-Invierno 2010. Córdoba, Argentina. Inédito.

SRUOGA P., LLAMBÍAS E.J., FAUQUÉ L., SCHONWANDT D., REPOL D.G. 2005. Volcanological and Geochemical Evolution of The Diamante Caldera - Maipo Volcano Complex in the Southern Andes of Argentina (34 $10^{\prime}$ S)". Journal of South American Earth Sciences, v. 19 (4) 401-406p.

TAUBER A.A. 2007. Primer yacimiento de huevos de dinosaurios (Cretácico Superior) de la provincia de La Rioja, Argentina. Ameghiniana v.44 n.1 Buenos Aires ene./mar 2007

TELLO G. y DEFAGO L. 2008. La geología en el relevamiento de circuitos de interés geológico. XVII Congreso Geológico Argentino, Jujuy. Actas. 951 p.

TCHILINGUIRIAN P., PEREYRA F.X., OLIVERA D.E. 2011. Geoarqueología y paleoambientes holocenos en la Puna Austral, provincia de Catamarca $\left(27^{\circ} \mathrm{S}\right)$. XVIII Congreso Geológico Argentino, Neuquén Actas (CD).

VALLECILLO G., LEÓN L., CABALLERO M.M., MENDOZA N. 2008. La educación geológica aplicada a la conservación de un área natural protegida: La Ciénaga de Huaco (San Juan, Argentina). XVII Congreso Geológico Argentino, Jujuy. Actas. 952953p.

VALLECILLO G., CABALLERO M.M. 2011. Área Protegida La Ciénaga de Huaco (San Juan): experiencia de trabajo geológico en proyectos de investigación y extensión. XVIII Congreso Geológico Argentino, Neuquén Actas (CD).

VATTUONE Sampietro M.M., SÁNCHEZ G. , MALDONADO M.G., ROLDÁN J., QUIROGA Villagra L.Y., NEDER L. 2011. Puesta en valor de sitios arqueológicos a cielo abierto: Hualfín como caso de estudio (Catamarca Argentina). XVIII Congreso Geológico Argentino, Neuquén Actas (CD).

VEJSBJERG, L., CALVO, J.O., HEREDIA, S. 2002. Criterios de valoración turística-recreativa de recursos geológicos , paleontológicos y paisajísticos. Caso Monumento Natural Parque de los Dinosaurios. Ciudad de Neuquén. En: Cabaleri N., Cingolani C.A., Linares E., López de Luchi, M.G., Ostera H., Panarello H.O. (Eds) XV Congreso Geológico Argentino. Calafate, Santa Cruz, Actas (CD).

VOGLINO D., 2008. Las barrancas del río Paraná en la provincia de Buenos Aires. Un escalón en la llanura. En: CSIGA (Ed.) Sitios de Interés Geológico de la República Argentina. Instituto de Geología y Recursos Minerales. Servicio Geológico Minero Argentino, Anales 46, II, Buenos Aires, 461-476p. 
VOTH, A. 2008. Los geoparques y el geoturismo: nuevos conceptos de valorización de recursos patrimoniales y desarrollo regional. En: Galve Martín, A. (Ed) XI Coloquio Ibérico de Geografía, Alcalá de Henares. 